\title{
MicroRNA-545-5p regulates apoptosis, migration and invasion of osteosarcoma by targeting dimethyladenosine transferase 1
}

\author{
HAI-ZHEN ZHOU*, BO CHEN*, XIAO-JU LI*, JUAN-JUAN DU, NAN ZHANG, \\ YU-XIONG SHAO, KUN ZHANG and ZHI-CHAO TONG
}

Department of Osteopathic Oncology, Honghui Hospital, Xi'an Jiaotong University, Xi'an, Shaanxi 710054, P.R. China

Received August 10, 2020; Accepted June 8, 2021

DOI: 10.3892/ol.2021.13024

\begin{abstract}
The metastasis of osteosarcoma is a major threat to both adolescents and young adults. Identifying novel targets that may prevent osteosarcoma metastasis is critical in developing advanced clinical therapies for treating this cancer. The present study aimed to explore the mechanism of microRNA (miR)-545-5p in the metastasis of osteosarcoma. The present study identified miR-545-5p as a potential target that was downregulated in both osteosarcoma clinical samples and cell lines, and in the latter, ectopically expressed miR-545-5p caused apoptosis. In addition, miR-545-5p exerted inhibitory effects in osteosarcoma migration and invasion. Overexpression of miR-545-5p induced xenograft growth inhibition in vivo. In addition, miR-545-5p targeted dimethyladenosine transferase 1 (DIMT1), an oncogenic protein that facilitates osteosarcoma proliferation, migration and invasion. Taken together, the results of the present study suggest that miR-545-5p functions as a tumor suppressor in osteosarcoma that promotes apoptosis, while inhibiting migration and invasion by targeting DIMT1. Taken together, the results of the present study suggest two potential novel targets for osteosarcoma treatment and metastasis prevention.
\end{abstract}

\section{Introduction}

Osteosarcoma is the most common malignant primary bone tumor and frequently undergoes distal metastasis, thus making it a severe threat to both adolescents and young adults (1). The 5-year survival rate of localized osteosarcoma has reached

Correspondence to: Dr Zhi-Chao Tong or Dr Kun Zhang, Department of Osteopathic Oncology, Honghui Hospital, Xi'an Jiaotong University, 555 Youyi East Road, Xi'an, Shaanxi 710054, P.R. China

E-mail: zhichaotong@126.com

E-mail: hhyyzk@126.com

*Contributed equally

Key words: microRNA-545-5p, apoptosis, metastasis, osteosarcoma, dimethyladenosine transferase 1
$80 \%$ in recent years due to major developments in clinical treatment (2). However, patients with metastatic osteosarcoma have a 5-year survival rate of only $20 \%$ (3). Although advanced therapies have been developed for distal metastases from osteosarcoma, knowledge on novel therapy targets that would prevent metastasis is still lacking $(4,5)$. Recent studies have demonstrated that non-coding RNAs play a critical role in osteosarcoma pathology, particularly during metastasis, which has prompted a search for novel strategies for osteosarcoma treatment and metastasis prevention (6-8). It is important to identify novel molecular mechanisms involved in osteosarcoma metastasis.

MicroRNAs (miRNAs/miRs) are small, non-coding RNAs that play critical roles in almost all cellular processes via post-transcriptional regulation of mRNAs, including cancer cell metastasis (9). miRNAs are involved at each step of development of osteosarcoma $(10,11)$. RNA sequencing of osteosarcoma tissues and pulmonary metastatic osteosarcoma tissues has led to the identification of miRNAs, long non-coding RNAs and mRNAs with differential expression in primary osteosarcoma, pulmonary metastatic osteosarcoma and normal controls, and has uncovered the molecular mechanisms and signaling networks that contribute to osteosarcoma progression (6). However, only a few differentially expressed miRNAs have been identified, including miR-340, miR-323-3p and miR-193a-3p/5p $(6,12,13)$. miR-545-5p has recently been reported to be upregulated in metastatic colorectal cancer cells compared with its localized strain (14), suggesting that miR-545-5p plays a role in cancer cell metastasis. Currently, only a single downstream target of miR-545-5p, delta-aminolevulinic acid dehydratase (15), which is a critical regulator of heme biosynthesis and pigmentation in invertebrates $(16,17)$, has been identified. Reportedly, miR-545 serves as a tumor regulator in different types of cancer, including hepatocellular carcinoma, cervical cancer and oral squamous cell carcinoma (18-20). Recently, Miao et al (21) demonstrated that downregulation of miR-545-5p expression in colon adenocarcinoma is associated with the survival and proliferation of colon cancer cells. However, the role of miR-545-5p in osteosarcoma remains unclear.

The present study aimed to further reveal the role of miR-545-5p in the metastasis of osteosarcoma, by determining the expression of miR-545-5p in clinical osteosarcoma samples and Saos-2, U2OS and MG63 osteosarcoma cell lines, and by 
assessing its roles in apoptosis and metastasis by transfection with miR-545-5p mimics in osteosarcoma cell lines. This study may help to provide new insights on the understanding and prevention of osteosarcoma metastasis.

\section{Materials and methods}

Clinical samples and cell culture. A total of 40 patients with osteosarcoma (32 men and 8 women; mean age \pm SD, 30.82 \pm 5.92 ; age range, $18-48$ years) at Honghui Hospital (Xi'an, China) were enrolled in the present study between May 2018 and April 2019. The inclusion criteria were that all patients were diagnosed by pathological and imaging examination and all cases were newly diagnosed. The exclusion criteria were as follows: i) Recurrent patients; ii) patients who had received immunotherapy, radiotherapy or chemotherapy and iii) patients with multiple newly diagnosed clinical disorders. Tumor tissues and adjacent normal tissues $(0.5 \mathrm{~cm}$ from the tumor boundary) were collected via surgical resection. Both RNAs and proteins were extracted from the samples and conserved in liquid nitrogen $\left(-196^{\circ} \mathrm{C}\right)$ for subsequent experimentation. The present study was approved by the Ethics Committee of Honghui Hospital (Xi'an, China; approval no. 202003059) and written informed consent was provided by all patients prior to the study start.

The human osteoblast cell line, hFOB1.19, and osteosarcoma cell lines, Saos-2, U2OS and MG63 were purchased from The Cell Bank of Type Culture Collection of The Chinese Academy of Sciences, and cultured according to the manufacturer's instructions. Briefly, cryopreserved hFOB1.19 cells were recovered from liquid nitrogen using the AccuVital cell recovery kit (AccuRef Scientific) and cultured in 1:1 mixture of F12 medium (SH30023.01, HyClone; Cytiva) and DMEM (SH30021.01; HyClone; Cytiva), with $2.5 \mathrm{mM}$ L-glutamine (25030149; Gibco; Thermo Fisher Scientific,

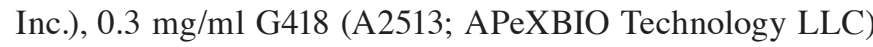
and $10 \%$ fetal bovine serum (FBS, 10099141; Gibco; Thermo Fisher Scientific, Inc.). Saos-2 and U2OS cells were maintained in McCoy's 5A medium (16600082; Gibco; Thermo Fisher Scientific, Inc.) supplemented with 15\% FBS. MG63 cells were maintained in MEM (MEL06-500ML; Caisson Labs) supplemented with $10 \%$ FBS. All cells were cultured at $37^{\circ} \mathrm{C}$ with $95 \%$ air and $5 \% \mathrm{CO}_{2}$.

In situ hybridization of miR-545-5p. In situ hybridization was performed as previously described (18). The miR-545-5p probe tagged with Digoxigenin (DIG) modifications and modified with Locked Nucleic Acid (LNA) nucleotides was purchased from Redlandbio Technology. On day 1, 4- $\mu \mathrm{m}$ sections of the TMA blocks were placed in a heater at $60^{\circ} \mathrm{C}$ overnight to attach Super Frost Plus Slides (Thermo Fisher Scientific, Inc.). Next, sections were deparaffinized with xylene twice for 5 min, rehydrated with an ethanol gradient, washed with DEPC water for $1 \mathrm{~min}$ and digested with proteinase $\mathrm{K}(15 \mu \mathrm{g} / \mathrm{ml}$; MilliporeSigma) in $\mathrm{PK}$ buffer [5 mM Tris- $\mathrm{HCl}(\mathrm{pH} 7.5)$ and $1 \mathrm{mM} \mathrm{NaCl}]$ at $37^{\circ} \mathrm{C}$ for $10 \mathrm{~min}$. After this, TMAs were rehydrated with ethanol and air-dried, followed by denaturing of LNA-probes at $90^{\circ} \mathrm{C}$ for $5 \mathrm{~min}$. Following this, LNA-probes miR-545-5p (25 nM) against miR-545-5p were incubated with the samples at $60^{\circ} \mathrm{C}$ for $5 \mathrm{~min}$ and then at $37^{\circ} \mathrm{C}$ overnight. On day 2, samples were washed with saline sodium citrate and $2 \%$ bovine serum albumin for $5 \mathrm{~min}$ at $4^{\circ} \mathrm{C}$ twice and incubated with anti-DIG/alkaline phosphate conjugated antibody (dilution, 1:400; cat. no. 11207733910 ; MilliporeSigma) at $37^{\circ} \mathrm{C}$ for $0.5 \mathrm{~h}$. Next, the blue color was generated by incubation with with Alexa Fluor 488-labeled antibody (dilution, 1:100; cat. no. A-11078; Invitrogen; Thermo Fisher Scientific, Inc.) at $37^{\circ} \mathrm{C}$ for $1 \mathrm{~h}$. The slides were then washed with TBS twice at room temperature and mounted using prolong gold anti-fade reagent with DAPI (cat. no. P36935; Invitrogen; Thermo Fisher Scientific, Inc.). Slides were air dried in a dark room overnight and covered with nail polish before imaging in a Zeiss LSM 880 inverted confocal microscope (Carl Zeiss AG).

Cell proliferation assay. The Cell Counting Kit-8 (CCK-8) assay (AccuRef Scientific) was performed to detect cell proliferation, according to the manufacturer's instructions. Briefly, $2 \times 10^{3}$ cells were plated into a 96-well plate and technical repeats were performed in triplicate. After 24 seeding, cells were transfected with $\mathrm{miR}-545-5 \mathrm{p}$ mimic with or without co-transfection of DIMT1 overexpressing plasmid using Lipofactamine ${ }^{\circledR} 2000$ (Invitrogen; Thermo Fisher Scientific, Inc.) according to the manufacturer's protocols. The cells were incubated at $37^{\circ} \mathrm{C}$ for $48 \mathrm{~h}$. Following $48 \mathrm{~h}$ of transfection, $10 \mu \mathrm{l}$ of CCK-8 solution was added to each well and incubated at $37^{\circ} \mathrm{C}$ for $2 \mathrm{~h}$. The optical density of each sample was measured at a wavelength of at $450 \mathrm{~nm}$, using a microplate reader (Thermo Fisher Scientific, Inc.).

In addition, the EdU assay was performed using an EdU proliferation kit (AccuRef Scientific), according to the manufacturer's instructions. A total of $2 \times 10^{3}$ cells were seeded into a 96-well plate and incubated with $20 \mu \mathrm{M}$ EdU for $2 \mathrm{~h}, 24 \mathrm{~h}$ post-seeding. Subsequently, cells were fixed with $4 \%$ paraformaldehyde at room temperature for $30 \mathrm{~min}$ and stained with EdU additive solution at room temperature for $2 \mathrm{~h}$. Samples were analyzed using a MoFlo Astrios cell sorter (Beckman Coulter, Inc.).

Cell transfection. miR-545-5p inhibitor (50 nM, 5'-UCAUCU AAUAAACAUUUACUGA-3'), inhibitor negative control (NC, $50 \mathrm{nM}, 5^{\prime}$-AACCUUUAGGGUUCUAGGGAGG-3'), miR-545-5p mimic (50 nM, 5'-UCAGUAAAUGUUUAUUAG AUGA-3') and mimic NC (50 nM, 5'-UUGUACUACACA AAAGUACUG-3') were purchased from Changzhou Ruibo Bio-Technology Co., Ltd. Specific small interfering (si)RNAs against DIMT1 (si-DIMT1, 50 nM, 5'-CCATAATATTGTCAG TGCT-3') and si-NC (50 nM. 5'-CACUGAUUUCAAAUG GUGCUAUU-3') were synthesized by Shanghai GenePharma Co., Ltd. The plasmid construction and the corresponding NC were also synthesized by Shanghai GenePharma Co., Ltd. Plasmid transfection technology was applied to overexpress DIMT1, with empty vector as its control. All transfections were performed using Lipofectamine ${ }^{\circledR} 2000$ (Invitrogen; Thermo Fisher Scientific, Inc.), according to the manufacturer's protocol. Briefly, miR-545-5p mimic, miR-545-5p inhibitor, DIMT1 siRNA or plasmid $(10 \mu \mathrm{g})$ were diluted in serum-free MEM (Caisson Labs) or McCoy's 5A medium (Gibco; Thermo Fisher Scientific, Inc.), mixed with Lipofectamine ${ }^{\circledR} 2000$, and incubated for $20 \mathrm{~min}$ at room temperature. Subsequently, cells were incubated with the transfected mixture at $37^{\circ} \mathrm{C}$ 
with $5 \% \mathrm{CO}_{2}$. Following incubation for $6 \mathrm{~h}$, the medium was replaced with MEM or McCoy's 5A medium containing $10 \%$ FBS, and cells were harvested and subjected to subsequent experimentation $48 \mathrm{~h}$ post-transfection. Transfection efficiency was assessed via reverse transcription-quantitative (RT-q)PCR analysis.

$R T$-qPCR. RNA was extracted from tissues or cells using TRIzol ${ }^{\circledR}$ reagent (cat. no. 15596-018, Invitrogen; Thermo Fisher Scientific, Inc.), according to the manufacturer's instructions. RT was performed using $500 \mu \mathrm{g}$ RNA and the PrimeScript ${ }^{\mathrm{TM}}$ RT reagent kit (cat. no. RR047A; Takara Biotechnology Co., Ltd.) according to the manufacturer's protocol. qPCR was subsequently performed using SYBR Green (cat. no. RR420A; Takara Biotechnology Co., Ltd.) in an ABI 7500 Real time PCR instrument (Applied Biosystems) using the following conditions: $95^{\circ} \mathrm{C}$ for $5 \mathrm{~min}$, followed by 40 cycles of $95^{\circ} \mathrm{C}$ for $15 \mathrm{sec}, 58^{\circ} \mathrm{C}$ for $30 \mathrm{sec}$ and $72^{\circ} \mathrm{C}$ for $10 \mathrm{sec}$. Fold-changes were calculated using the $2^{-\Delta \Delta \mathrm{Cq}}$ method (22). Each sample was analyzed in triplicate. The following primer sequences were used for qPCR: DIMT1 forward, 5'-GGCTGCCTT AAGACCAACTG-3' and reverse, 5'-CGTGCCCTGAAC TCTTTTGT-3'; GAPDH forward, 5'-ACCAGGAAATGA GCTTGACA-3' and reverse, 5'-GACCACAGTCCATGCCAT C-3'; miR-545-5p forward, 5'-TCAGTAAATGTTTATTAG ATGA-3' and reverse, universal oligo(dT) reverse primer; and U6 forward, 5'-CTCGCTTCGGCAGCACA-3' and reverse, 5'-AACGCTTCACGAATTTGCGT-3'.

Cell apoptosis analysis. Cell apoptosis was analyzed using the Annexin V-FITC Apoptosis kit (cat. no. K101; Biovision, Inc.), according to the manufacturer's instructions. Briefly, cells were seeded into 6-well plates at a density of $3 \times 10^{5}$ cells/well and transfected with miR-545-5p mimic with or without co-transfection of DIMT1 overexpressing plasmid for $48 \mathrm{~h}$. Cells were collected and washed with PBS. Following resuspension with Annexin binding buffer, cells were labeled with Annexin V-FITC for $15 \mathrm{~min}$ at $4^{\circ} \mathrm{C}$ followed by incubation with propidium iodide (PI) for $5 \mathrm{~min}$ at $4^{\circ} \mathrm{C}$. Apoptotic cells were subsequently analyzed using a flow cytometer (FACSCanto II; BD Biosciences) and CellQuest 3.0 software (BD Biosciences).

Wound healing assay. Following the indicated treatments, a monolayer of Saos-2 or MG63 cells was scratched using a 10- $\mu$ l pipette tip. Scratched cells were removed by rinsing twice with PBS. Cells were incubated at $37^{\circ} \mathrm{C}$ for an additional $48 \mathrm{~h}$ in serum-free DMEM. The wound of each sample was pictured at 0 and $48 \mathrm{~h}$ using a light microscope (Olympus Corporation) at x200 magnification. The wound distances were quantitatively evaluated using ImageJ software (version 1.49; National Institutes of Health), as previously described (23). Each wound healing analysis was repeated in triplicate, using independent samples.

Transwell invasion assay. A Transwell invasion analysis was performed as previously described (24). Briefly, a 1:1 mix of matrigel and the indicated growth medium was used to coat the Transwell (Costar). The coated Transwell was then incubated at $37^{\circ} \mathrm{C}$ for $1 \mathrm{~h}$ before $1 \times 10^{5}$ cells/well were seeded to the upper chamber, each with three replicates. The lower chamber was flooded with culture medium containing $10 \%$ FBS. After $24 \mathrm{~h}$ of culture, the cells were fixed with $4 \%$ polyoxymethylene and stained with crystal violet at room temperature for $15 \mathrm{~min}$. Following this, the stained results were captured and analyzed under a light microscope (Olympus Corporation) at magnification of $\times 200$.

Western blotting. Protein collection and western blot analysis were performed as previously described (25). Cells and tissue samples were lysed on ice for $30 \mathrm{~min}$ using RIPA lysis buffer [50 mM Tris (pH 7.4), $150 \mathrm{mM} \mathrm{NaCl,} \%$ NP-40, 0.5\% sodium deoxycholate; Beijing Solarbio Science \& Technology Co., Ltd.] before centrifuging at $4^{\circ} \mathrm{C}, 17,000 \mathrm{x} g$ for $30 \mathrm{~min}$. Proteins were quantified using the bicinchoninic acid assay method (Thermo Fisher Scientific, Inc.), and equivalent protein $(25 \mu \mathrm{g})$ was loaded to each lane and separated on $10 \%$ gels using SDS-PAGE. Following this, proteins were transferred to polyvinylidene fluoride membrane and blocked with 5\% skimmed milk solution at room temperature for $1 \mathrm{~h}$. Subsequently, membranes were incubated with mouse anti-human primary antibodies against DIMT1 (cat. no. ab69434; Abcam) and rabbit anti-human GAPDH (cat. no. ab97627; Abcam) at $4^{\circ} \mathrm{C}$ overnight. After this, membranes were incubated with the rat anti-mouse (cat. no. ab6728; Abcam) or mouse anti-rabbit (cat. no. ab99697; Abcam) secondary antibody at room temperature for $1 \mathrm{~h}$. Finally, protein bands were visualized using a chemiluminescence kit (cat. no. AR21PN003; AccuRef Scientific) and qualified using ImageJ software (version 1.49; National Institutes of Health).

In vivo analysis of tumor growth. For the subcutaneous xenograft study, 8-week-old male BALB/c nude mice $(n=16$, 20-25 g) were purchased from the Laboratory Animal Center of Xi'an Jiaotong University, and housed at $25^{\circ} \mathrm{C}$ with a $12 \mathrm{~h}$ light/dark cycle. The mice were reared under specific pathogen-free conditions $\left(25^{\circ} \mathrm{C}\right.$ with $55 \%$ humidity), with free access to food and water.

A total of $3 \times 10^{6}$ Saos- 2 or MG63 cells transfected with control miRNA (mimic NC) or miR-545-5p mimics for $24 \mathrm{~h}$ were trypsinized, resuspend in PBS and subcutaneously injected into the left or right back of each mouse. The xenografts were measured every 2 days and their volumes were calculated using the following formula: $a \mathrm{xb}^{2} / 2$ [where (a) is the largest, and (b) is the smallest]. The mice were euthanized by $\mathrm{CO}_{2}$ inhalation $\left(\mathrm{CO}_{2}\right.$ flow rate, $30 \%$ of cage volume) (26) 14 days post-transplantation and mortality was confirmed via cessation of heartbeat. The tumor tissues were dissected, photographed and weighed. RNA was subsequently extracted from the xenografts and RT-qPCR analysis. All animal experiments were performed in accordance with the Guide for the Care and Use of Laboratory Animals of the National Institutes of Health (27) and approved by the Animal Care and Use Committee of Hong Hui Hospital, Xi'an Jiaotong University (Xi'an, China; approval no. 202003059).

Dual-luciferase reporter assay. DNA fragments containing wild-type (WT) or mutated (MUT) DIMT1 DNA binding sites were synthesized by BGI. (https://en.genomics.cn/), and cloned into a pGL3 firefly reporter plasmid (Promega Corporation). All plasmids were purchased from Guangzhou RiboBio Co., 
Ltd. Cells were cultured to a confluence of 70-80\% in 24-well plates, followed by transfection with $100 \mathrm{ng}$ pGL3-WT or pGL3-MUT, $20 \mathrm{ng}$ of the transfection control Renilla vector (pRL-TK; Promega Corporation) and $100 \mathrm{nM}$ miR-545-5p mimic or mimic NC (Guangzhou RiboBio Co., Ltd.), using $1 \mu \mathrm{l}$ Lipofectamine ${ }^{\circledR} 2000$ (Invitrogen; Thermo Fisher Scientific, Inc.) according to the manufacturer's protocol. After 2 days, luciferase activities were detected via the dual-luciferase reporter assay (Promega Corporation). The firefly luciferase activity was normalized to Renilla luciferase activity, and the relative luciferase activity in each group was calculated using the ratio of firefly luciferase activity to Renilla luciferase activity compared with that of the NC group.

Target prediction. miR-545-5p targeted candidate genes and the binding sites of miR-545-5p were predicted using the online tools, TargetScanV7.2 (http://www.targetscan. org/vert_72), miRDB (http://www.mirdb.org/mirdb/index. html) and DIANA-microT (http://diana.imis.athena-innovation. gr/DianaTools/index.php?r=microT_CDS/index). The following parameters were set for each database: DIANA-microT (miTG score $\geq 0.8$ ); miRDB (Target score $\geq 80$ ) and TargetScan (Cumulative weighted context++ score $\leq-0.5$ ). The Venn diagram was constructed using VENNY 2.1(https://bioinfogp. cnb.csic.es/tools/venny). The miRNA-mRNA regulation network was constructed using Cytoscape (version 3.6.1) (27).

Immunohistochemistry staining. The protein expression of DIMT1 in clinical samples was determined using immunohistochemistry. Briefly, clinical tissue samples were washed with PBS to remove blood on the surface and fixed with $4 \%$ formaldehyde at $4^{\circ} \mathrm{C}$ for $48 \mathrm{~h}$. The tissues were then dehydrated with gradient ethanol and paraffin-embedded at $60^{\circ} \mathrm{C}$ overnight. Tissues were cut into $5-\mu \mathrm{m}$ thick sections, heated at $60^{\circ} \mathrm{C}$ for $1 \mathrm{~h}$, de-waxed using xylene and rehydrated with gradient alcohol. Following this, antigens on sections were retrieved using a microwave oven and boiled $0.01 \mathrm{M}$ citrate buffer ( $\mathrm{pH} 6.0)$ for $3 \mathrm{~min}$, three times at 5 -min intervals. After this, sections were incubated with $3 \% \mathrm{H}_{2} \mathrm{O}_{2}$ for $10 \mathrm{~min}$ at room temperature to block endogenous peroxidase. Next, sections were blocked with $5 \%$ goat serum (Beyotime Institute of Biotechnology) at room temperature for $1 \mathrm{~h}$. The sections were then incubated with mouse anti-human DIMT1 antibody (dilution, 1:500; cat. no. HPA042944; MilliporeSigma) overnight at $4^{\circ} \mathrm{C}$. The next day, sections were incubated with donkey anti-rabbit secondary antibody (dilution, 1:400; cat. no. ab207999; Abcam) at room temperature for $1 \mathrm{~h}$ and visualized using a DAB Substrate kit (cat. no. ab64238; Abcam) according to the manufacturer's protocol. The nuclei on the sections were counterstained with hematoxylin at room temperature for 5-10 min and washed with running water. Following this, sections were dehydrated with ethanol, hyalinized by xylene and mounted with neutral resins (cat. no. E675007; Sangon Bioteck Co. Ltd.). Subsequently, images of the sections were captured and analyzed under a light microscope (Olympus Corporation).

Statistical analysis. Statistical analysis was performed using GraphPad Prism 5.0 software (GraphPad Software, Inc.).
All experiments were performed in triplicate and data are presented as the mean \pm SD. Paired Student's t-test was used to compare differences between tumor tissues and adjacent normal tissues. Unpaired Student's t-test was used to compare differences between two groups, while one-way ANOVA followed by Tukey's post hoc test were used to compare differences between multiple groups. According to the median value of miR-545-5p expression, patients were divided into the high and low expression groups, and comparisons between them were compared with $\chi^{2}$ analysis. $\mathrm{P}<0.05$ was considered to indicate a statistically significant difference.

\section{Results}

miR-545-5p expression is downregulated in osteosarcoma. To understand the role that miR-545-5p plays in osteosarcoma, RT-qPCR analysis was performed to detect miR-545-5p expression in both clinical osteosarcoma tissues and adjacent normal tissues. The results demonstrated that miR-545-5p expression was significantly downregulated in osteosarcoma tissues compared with adjacent normal tissues $(\mathrm{P}<0.05$; Fig. 1A). miR-545-5p expression was also detected in osteosarcoma cell lines. The results demonstrated that miR-545-5p expression was downregulated in all three osteosarcoma cell lines compared with the human normal osteoblast cell line, hFOB1.19, and its expression was downregulated by $>50 \%$ in Saos-2 and MG63 cells ( $\mathrm{P}<0.05$; Fig. 1B). To confirm these results, in situ hybridization was performed for miR-545-5p in clinical osteosarcoma tissues and adjacent normal tissues. The results revealed a notable decrease in the number of miR-545-5p positive cells in osteosarcoma tissues compared with adjacent normal tissues (Fig. 1C).

To determine the clinical significance of miR-545-5p in patients with osteosarcoma, the association between miR-545-5p expression and the clinicopathological characteristics of 40 patients with osteosarcoma was assessed. Based on the median miR-545-5p expression level in clinical samples, patient samples were grouped into either a high or low expression groups ( $\mathrm{n}=10$ for each group). The results demonstrated that miR-545-5p expression was significantly associated with tumor size, metastasis and differentiation (all $\mathrm{P}<0.05$; Table I).

miR-545-5p inhibits the proliferation, migration and invasion of osteosarcoma cells. To determine the role of miR-545-5p in osteosarcoma, cells were transfected with miR-545-5p mimics to increase miR-545-5p expression in osteosarcoma cells (Fig. S1A). Notably, the proliferation of Saos-2 and MG63 cells decreased following overexpression of miR-545-5p (both $\mathrm{P}<0.05$; Fig. 2A). The EdU assay was performed to detect the proliferation of osteosarcoma cells, and the results demonstrated that overexpression of miR-545-5p inhibited the proliferation of Saos-2 and MG63 cells (both $\mathrm{P}<0.05$; Fig. 2B). Notably, transfection with miR-545-5p mimics significantly induced apoptosis of both Saos-2 and MG63 cells (both $\mathrm{P}<0.05$; Fig. 2C). The Transwell and wound healing assays were performed to evaluate the effect of miR-545-5p overexpression on the invasion and migration of osteosarcoma cells, respectively. The results demonstrated that the number of cells infiltrating through the Matrigel significantly decreased following transfection with miR-545-5p mimics (both 

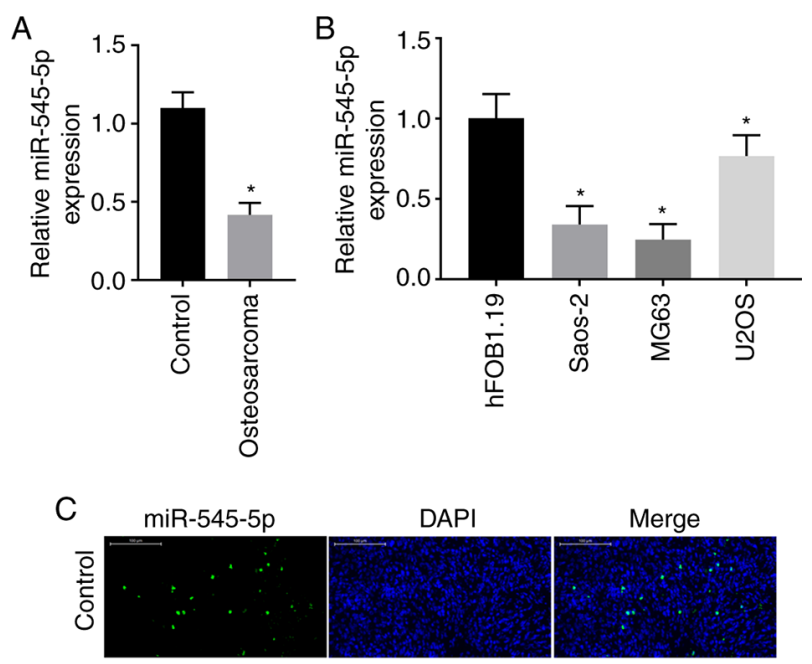

$$
\begin{aligned}
& \frac{\pi}{5} \\
& \overline{0} \\
& \frac{0}{\sigma} \\
& 0 \\
& 0 \\
& \frac{0}{w} \\
& 0
\end{aligned}
$$

Figure 1. miR-545-5p expression is downregulated in osteosarcoma (A) RT-qPCR analysis was performed to detect miR-545-5p expression in adjacent normal tissues and osteosarcoma tissues. (B) RT-qPCR analysis was performed to detect miR-545-5p expression in different osteosarcoma cell lines (MG63, U2OS and Saos-2) and hFOB1.19 cells. (C) Representative images of miR-545-5p expression via in situ hybridization in paired primary tumor tissues and adjacent normal tissues. Nuclei were stained with DAPI (blue) and miR-545-5p positive regions are highlighted in green. Scale bar, $100 \mu \mathrm{m}$. ${ }^{*} \mathrm{P}<0.05$ vs. adjacent normal tissues or hFOB1.19 cells. miR, microRNA; RT-qPCR, reverse transcription-quantitative PCR.

$\mathrm{P}<0.05$; Fig. 3A), suggesting that overexpression of miR-545-5p decreases the invasive ability of Saos-2 and MG63 cells. In addition, the wound healing speed decreased in both Saos-2 and MG63 cells following transfection with miR-545-5p mimics (both $\mathrm{P}<0.05$; Fig. $3 \mathrm{~B}$ ). Taken together, these results suggest that miR-545-5p facilitates apoptosis and inhibits the migratory and invasive abilities of osteosarcoma cells.

miR-545-5p restricts tumor growth. Given that the results of the present study demonstrated that miR-545-5p inhibited proliferation and promoted apoptosis of osteosarcoma cells, tumor growth in vivo was assessed following overexpression of miR-545-5p. Xenografts generated from MG63 $(\mathrm{P}<0.05$; Fig. 4A) and Saos-2 ( $\mathrm{P}<0.05$; Fig. 4D) cells, with ectopic miR-545-5p expression, were significantly smaller than those transfected with mimic NC. In addition, both the weight and volume of the xenografts generated from MG63 $(\mathrm{P}<0.05$; Fig. 4B and C) and Saos-2 ( $\mathrm{P}<0.05$; Fig. 4E and F) cells overexpressing miR-545-5p significantly decreased compared with the mimic NC group, suggesting that miR-545-5p exerts an antitumor effect in vivo.

DIMT1 is a downstream target of miR-545-5p. To determine the underlying molecular mechanism by which miR-545-5p regulates osteosarcoma progression, downstream miR-545-5p targets were predicted using the online databases, DIANA-microT, miRDB and TargetScan. The following parameters were set for each database: DIANA-microT (miTG score $\geq 0.8$ ); miRDB (Target score $\geq 80$ ) and TargetScan
Table I. Association between miR-545-5p expression and the clinicopathological characteristics of patients with osteosarcoma $(n=40)$.

\begin{tabular}{|c|c|c|c|}
\hline \multirow[b]{2}{*}{ Characteristic } & \multicolumn{2}{|c|}{ miR-545-5p expression } & \multirow[b]{2}{*}{ P-value } \\
\hline & Low $(n=20)$ & High $(n=20)$ & \\
\hline Age, years & & & 0.525 \\
\hline$<55$ & 10 & 12 & \\
\hline$\geq 55$ & 10 & 8 & \\
\hline Sex & & & 0.236 \\
\hline Male & 18 & 14 & \\
\hline Female & 2 & 6 & \\
\hline Tumor size, $\mathrm{cm}$ & & & 0.025 \\
\hline$<3$ & 15 & 8 & \\
\hline$>3$ & 5 & 12 & \\
\hline Location & & & 0.185 \\
\hline Tibia/femur & 17 & 25 & \\
\hline Elsewhere & 13 & 5 & \\
\hline Clinical stage & & & 0.507 \\
\hline I & 14 & 12 & \\
\hline II & 6 & 8 & \\
\hline Distant metastasis & & & 0.018 \\
\hline Absent & 16 & 12 & \\
\hline Present & 4 & 8 & \\
\hline TNM stage & & & 0.011 \\
\hline I-II & 13 & 5 & \\
\hline III-IV & 7 & 15 & \\
\hline Differentiated degree & & & 0.044 \\
\hline High/middle & 15 & 6 & \\
\hline Low/undifferentiated & 5 & 14 & \\
\hline
\end{tabular}

miR, microRNA; TNM, Tumor-Node-Metastasis.

(Cumulative weighted context++ score $\leq-0.5)$. With these parameters, 14 potential downstream target genes were identified (Fig. 5A). RT-qPCR analysis was performed to detect the expression levels of all 14 genes in Saos-2 cells transfected with miR-545-5p inhibitor. The results demonstrated that transfection with miR-545-5p inhibitor significantly upregulated DIMT1 expression compared with cells transfected with inhibitor $\mathrm{NC}(\mathrm{P}<0.001$; Fig. 5B).

To determine the direct regulatory association between miR-545-5p and DIMT1, luciferase reporter plasmids carrying WT DIMT1 3'-untranslated region (UTR) sequence (DIMT1-WT) or a DIMT1 3'-UTR sequence with mutated binding sites (DIMT1-MUT) were co-transfected with miR-545-5p mimics or mimic NC into osteosarcoma cells (Fig. 5C). The results demonstrated that in both Saos-2 and MG63 cells, luciferase activities were significantly inhibited when miR-545-5p was co-transfected with luciferase reporter plasmids carrying DIMT1-WT ( $<<0.05$; Fig. 5C). Notably, miR-545-5p had no effect on the mutated DIMT1 3'-UTR, suggesting that miR-545-5p binds to the mRNA of DIMT1 via the complementary sequences predicted (Fig. 5C). 

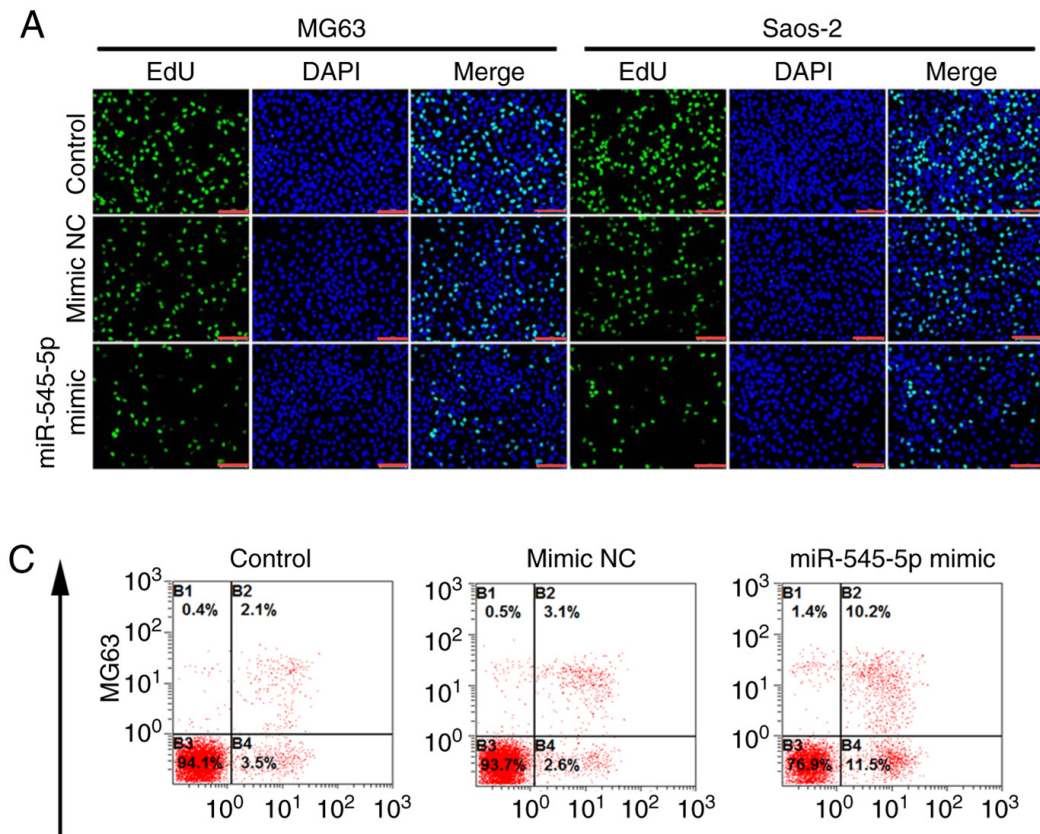

$\bar{\alpha}$

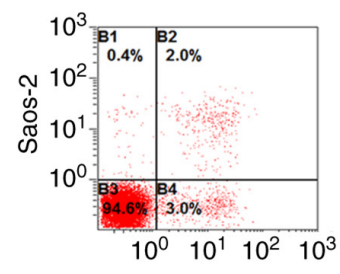

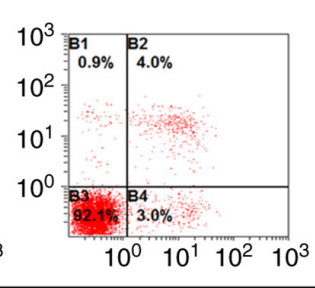

Annexin V-FITC

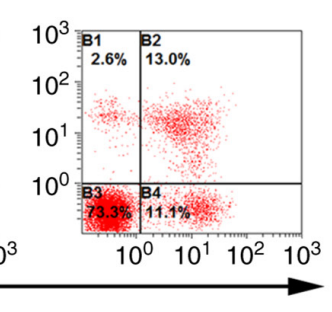

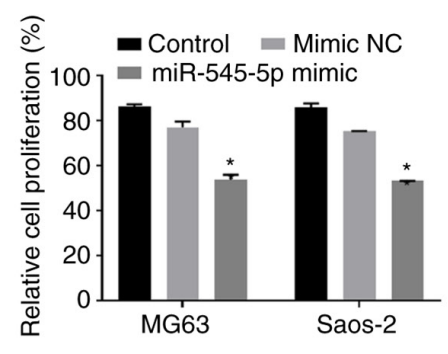
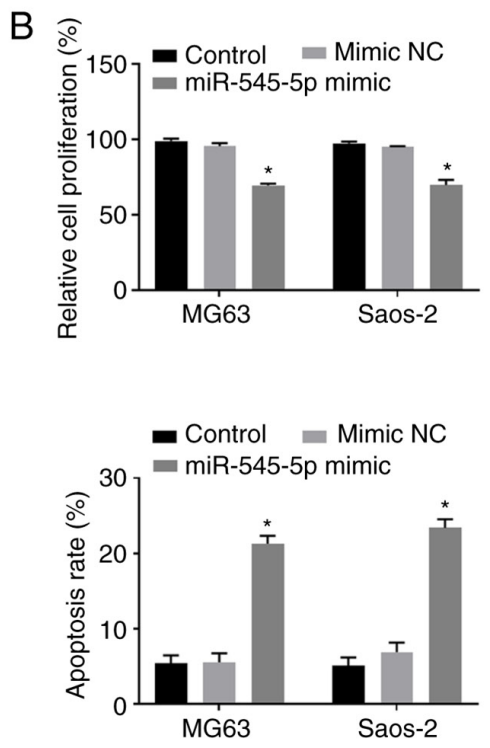

Figure 2. miR-545-5p facilitates osteosarcoma cell apoptosis. (A) 2x10³ MG63 or Saos-2 cells were transfected with miR-545-5p mimic or mimic NC for $48 \mathrm{~h}$ and proliferating cells were labeled with EdU. Nuclei were labeled with DAPI (blue) and EdU-positive cells are highlighted in green. The number of proliferating cells were quantified using Image J software version 1.49. Cells without transfection were also analyzed (control). (Scale bar, $50 \mu \mathrm{m}$ and magnification, x100). (B) The Cell Counting Kit-8 assay was performed to detect the viability of Saos-2 and MG63 cells transfected with miR-545-5p mimic of mimic $\mathrm{NC}$ for $48 \mathrm{~h}$. Cells without transfection were also analyzed (control). (C) 3x10 5 Saos-2 or MG63 cells transfected with 50 nM mimic NC or miR-545-5p mimic for $48 \mathrm{~h}$ were harvested and labeled with Annexin V-FITC and PI. Samples were assessed via flow cytometry. The numbers in each quadrant indicate positive percentages of the entire population. ${ }^{*} \mathrm{P}<0.05$ vs. control. miR, microRNA; NC, negative control; PI, propidium iodide.

Changes in DIMT1 mRNA and protein expression levels in MG63 cells were detected following transfection with mimic NC, miR-545-5p mimic, inhibitor NC or miR-545-5p inhibitor, respectively. The successful transfections of miR-545-5p mimic and miR-545-5p inhibitor were confirmed using RT-qPCR (Fig. S1A and B). Notably, transfection with miR-545-5p mimic suppressed DIMT1 expression $(\mathrm{P}<0.05)$, whereas transfection with miR-545-5p inhibitor significantly increased DIMT1 expression in Saos-2 cells $(\mathrm{P}<0.001$; Fig. 5D and E), confirming that DIMT1 is a downstream target of miR-545-5p. DIMT1 protein and mRNA expression levels were also detected in clinical samples via immunohistochemistry and RT-qPCR analyses. The results demonstrated that both DIMT1 protein and mRNA expression levels were upregulated in clinical osteosarcoma samples $(\mathrm{P}<0.05$; Fig. 5F and G).

DIMT1 facilitates metastasis of osteosarcoma. The present study investigated the role of DIMT1 in osteosarcoma. DIMT1 protein expression was detected in five clinical osteosarcoma samples and the results demonstrated that DIMT1 expression was upregulated in all samples compared with adjacent normal tissues (Fig. 6A). In addition, DIMT1 expression was notably upregulated in Saos-2 and MG63 cells compared with
hFOB1.19 human osteoblast cells (Fig. 6B). DIMT1 expression was knocked down at the mRNA level via transfection with siRNA, which decreased DIMT1 expression in both Saos-2 and MG63 cells (all P<0.05; Fig. 6C and D). Notably, DIMT1 knockdown significantly decreased the migratory and invasive abilities of Saos- 2 and MG63 cells (all $\mathrm{P}<0.05$; Fig. $6 \mathrm{E}$ and F). These results are similar to those observed following overexpression of miR-545-5p, suggesting that miR-545-5p functions by regulating DIMT1 expression.

miR-545-5p suppresses metastasis of osteosarcoma by targeting DIMT1. To further validate the function of miR-545-5p via DIMT1, miR-545-5p and DIMT1 were co-overexpressed in Saos-2 and MG63 cells $(\mathrm{P}<0.01$; Fig. S1C). The results demonstrated that overexpression of DIMT1 attenuated DIMT1 reduction induced by simultaneous overexpression of miR-545-5p (Fig. 7A). Notably, overexpression of DIMT1 in both Saos-2 and MG63 cells transfected with mi-545-5p mimics restored cell viability to similar levels as the mimic NC group (all $\mathrm{P}<0.05$; Fig. 7B). Furthermore, the migratory ability of both Saos-2 and MG63 cells was also rescued following overexpression of DIMT1 in cells transfected with miR-545-5p mimics (all $\mathrm{P}<0.05$; Fig. 7C). 

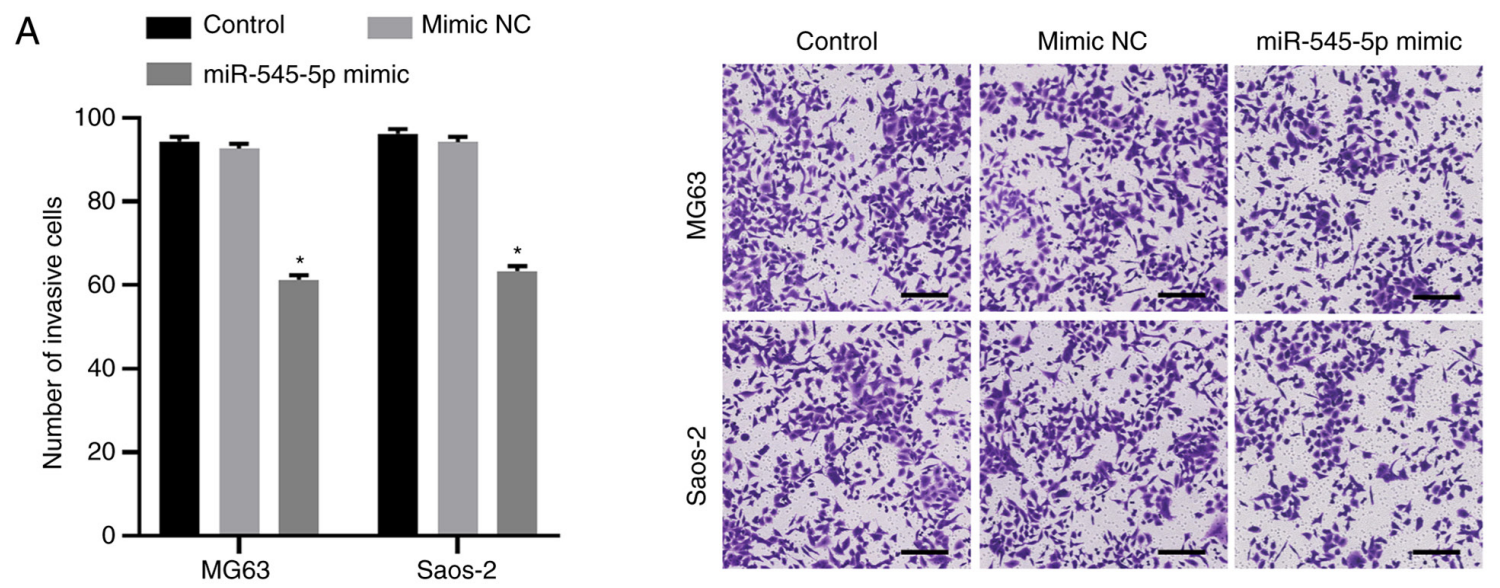

B

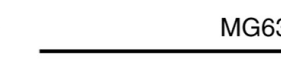

G63
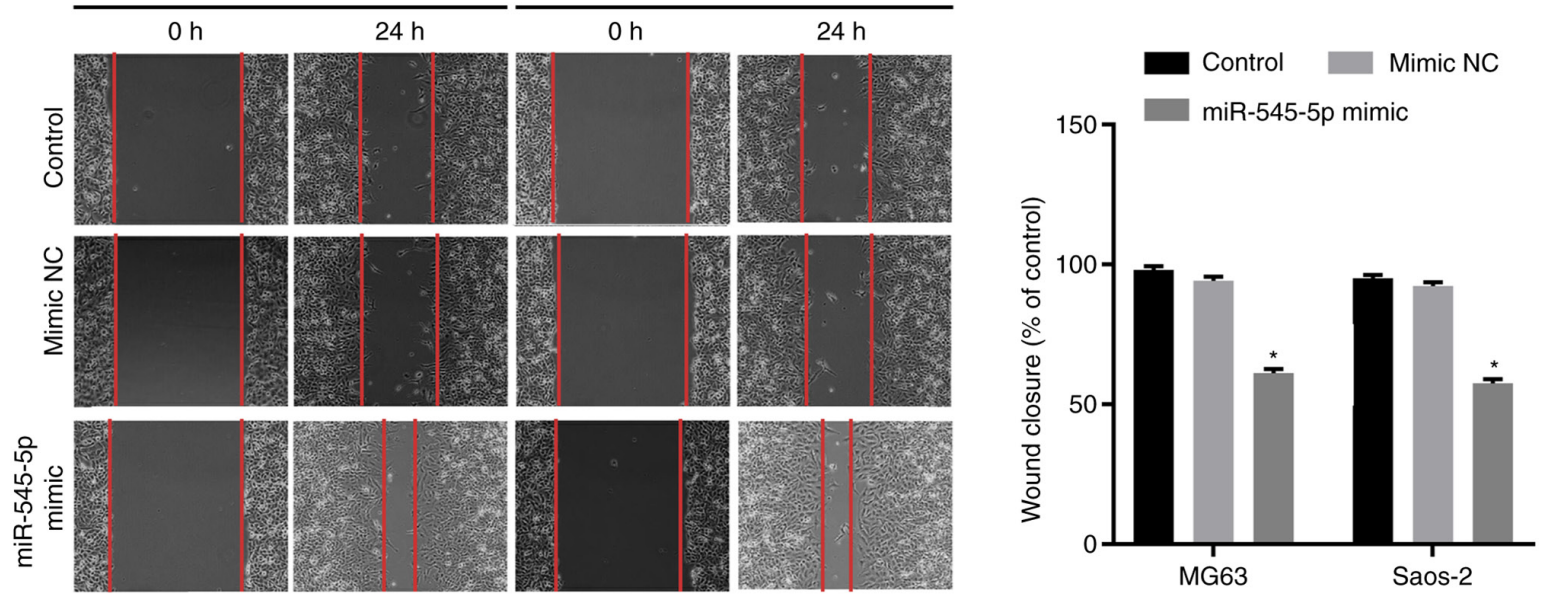

Figure 3. miR-545-5p inhibits osteosarcoma cell invasion and migration. (A) A total of $1 \times 10^{5}$ Saos-2 or MG63 cells were transfected with mimic NC or miR-545-5p mimic for $24 \mathrm{~h}$ and seeded into Transwell inserts for invasion analysis. Quantification results are depicted in the top left panel. Cells without transfection were also analyzed (control). Scale bar, $50 \mu \mathrm{m}$. (B) The wound healing assay was performed to assess the migratory ability of Saos-2 and MG63 cells transfected with mimic NC or miR-545-5p mimic. Quantification results are depicted in the bottom right panel. Cells without transfection were also analyzed (control). Scale bar, $50 \mu \mathrm{m} .{ }^{*} \mathrm{P}<0.05$ vs. control. miR, microRNA; NC, negative control.

To evaluate the effect of overexpressing DIMT1 on the apoptosis of osteosarcoma cells, flow cytometric analysis of cells labeled with Annexin V and PI was performed. The results demonstrated that overexpression of DIMT1 in Saos-2 and MG63 cells transfected with miR-545-5p mimics significantly decreased the percentage of apoptotic cells compared with the control group $(\mathrm{P}<0.05$; Fig. 7D). In addition, the migratory ability of Saos-2 and MG63 cells following co-overexpression with miR-545-5p and DIMT1 was assessed. The results demonstrated that overexpression of DIMT1 partially rescued the reduced migratory ability of Saos-2 and MG63 cells following overexpression of miR-545-5p (Fig. 7E), which suggests that miR-545-5p functions by inhibiting DIMT1 expression. Taken together, the results of the present study suggest that miR-545-5p functions as a tumor suppressor by targeting DIMT1.

The results of the present study demonstrated that miR-545-5p expression was downregulated in clinical osteosarcoma patient samples and cell lines. In addition, overexpression of miR-545-5p increased apoptosis, and inhibited migration and invasion of osteosarcoma cells by targeting DIMT1. Furthermore, overexpression of miR-545-5p successfully inhibited in vivo xenograft growth. Collectively, these results suggest that miR-545-5p is a novel miRNA that functions as a tumor suppressor in osteosarcoma, thus providing novel therapeutic targets for osteosarcoma.

\section{Discussion}

miRNA expression can be altered during the development of certain diseases, and thus may act as a critical biomarker for disease (28-30). The identification of novel miRNAs with altered expression levels in osteosarcoma may assist current therapeutic strategies since miRNAs are promising targets for drug development (31). The results of the present study demonstrated that miR-545-5p expression was downregulated in osteosarcoma. However, the role of miR-545-5p in cancer development remains unknown. To the best of our knowledge, the present study is the first to provide experimental evidence supporting the function of miR-545-5p in osteosarcoma development. However, to further clarify the role of this potential tumor suppressor, transgenic mice are required. miR-545-5p knockout mice will be used to further determine the anticancer role of this miRNA in an in vivo model. The results of the present study demonstrated that miR-545-5p has antiproliferative and proapoptotic roles in osteosarcoma. Notably, 
A

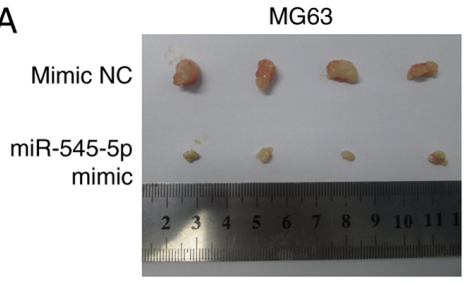

D

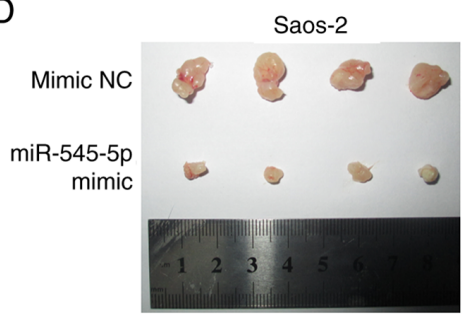

B

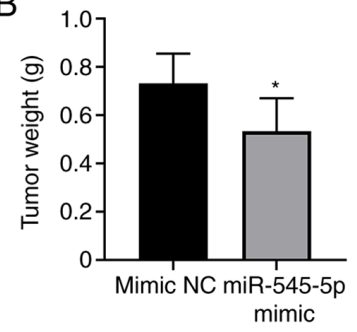

E

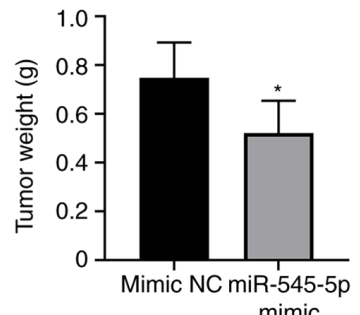

C

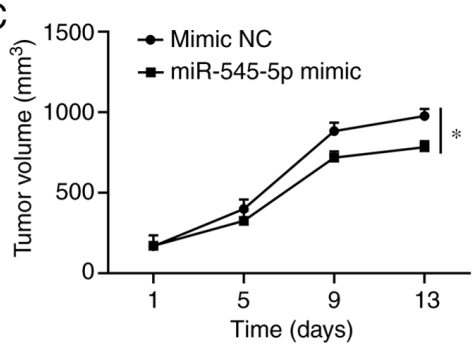

$\mathrm{F}$

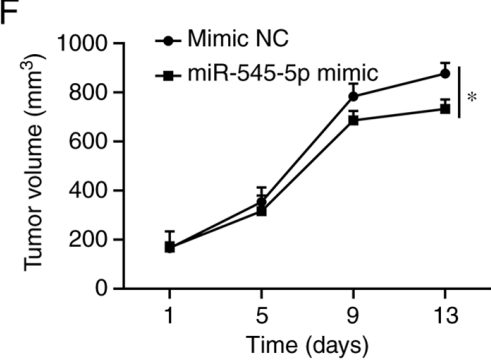

Figure 4. miR-545-5p inhibits tumor growth in vivo. A total of 3x $10^{6}$ Saos-2 or MG63 cells transfected with mimic NC or miR-545-5p mimic for $24 \mathrm{~h}$ were trypsinized and subcutaneously injected into BALB/c nude mice. The mice were sacrificed, and tumor tissues were dissected, photographed and weighed after 14 days. (A) Representative images for xenografts generated from MG63 cells transfected with mimic NC or miR-545-5p mimic. (B) Tumor weight and (C) volume of xenografts generated from MG63 cells transfected with mimic NC or miR-545-5p mimic. (D) Representative images for xenografts generated from Saos-2 cells transfected with mimic NC or miR-545-5p mimic. (E) Tumor weight and (F) volume of xenografts generated from Saos-2 cells transfected with mimic NC or miR-545-5p mimic. ${ }^{*}<<0.05$ vs. mimic NC. miR, microRNA; NC, negative control.

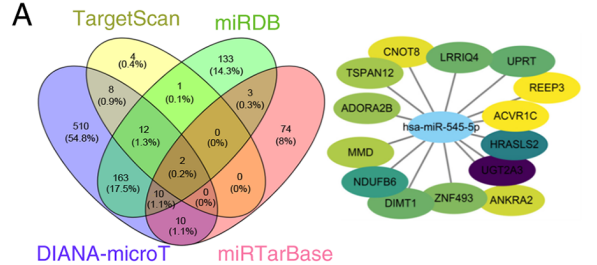

C

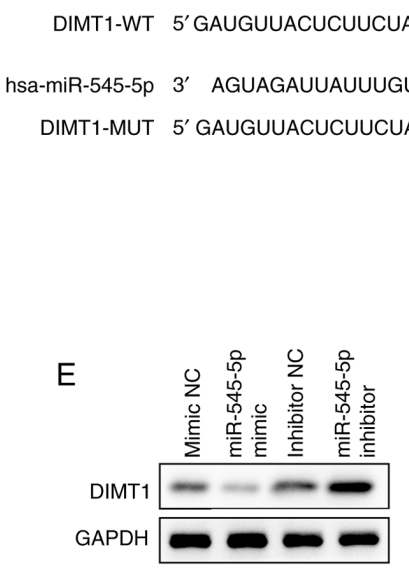

B

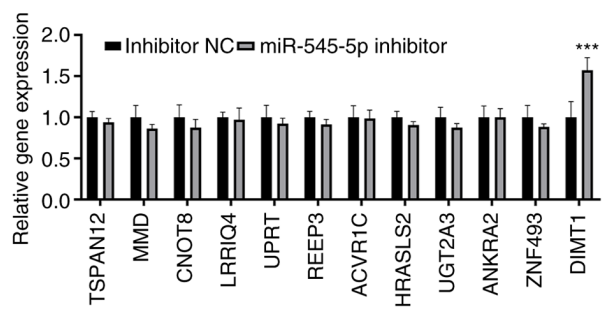

- Mimic NC $=$ miR-545-5p mimic
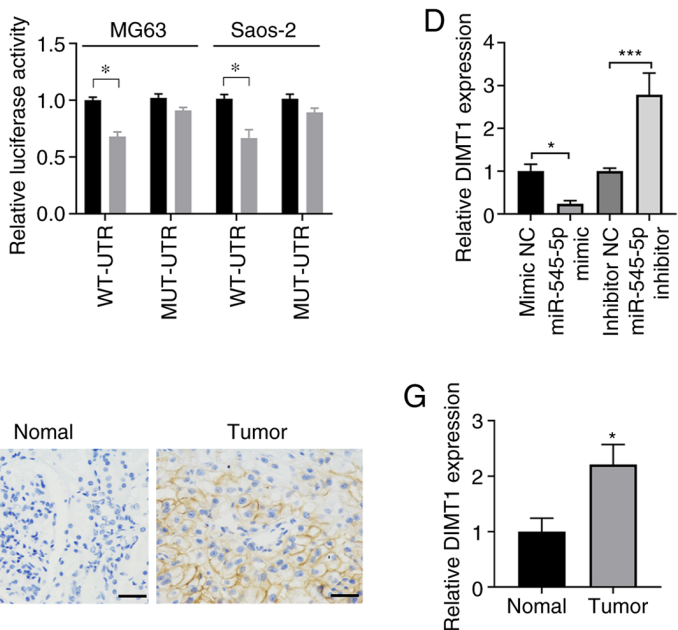

Figure 5. DIMT1 is a target of miR-545-5p. (A) DIANA-microT, miRDB and TargetScan were used to predict the target mRNAs of miR-545-5p. The Venn diagram depicts 14 potential targets. The regulation network of the 14 potential target mRNAs is depicted in the top right panel. The oval nodes represent miR-545-5p-targeted mRNAs. The darker the color, the greater the possibility. (B) Verification of potential targets in MG63 cells transfected with 50 nM miR-545-5p inhibitor or inhibitor NC. (C) Left panel: Sequence alignment depicting the potential interactions between miR-545-5p and DIMT1-WT or DIMT1-MUT 3'-UTR of DIMT1. Right panel: Luciferase reporter activities of Saos-2 and MG63 cells co-transfected with plasmid containing WT or MUT DIMT1 3'-UTR and miR-545-5p mimics or mimic NC. (D) RT-qPCR analysis was performed to detect DIMT1 exp ression in MG63 cells transfected with $50 \mathrm{nM}$ mimic NC, miR-545-5p mimic, inhibitor NC or miR-545-5p inhibitor. (E) Western blot analysis was performed to detect DIMT1 protein expression in MG63 cells transfected with $50 \mathrm{nM}$ mimic NC, miR-545-5p mimic, inhibitor NC or miR-545-5p inhibitor. (F) Representative immunohistochemistry staining of DIMT1 in osteosarcoma tissues and adjacent normal tissues. Scale bar, $50 \mu \mathrm{m}$ and magnification, x200. (G) RT-qPCR analysis was performed to detect miR-545-5p expression in osteosarcoma tissues and adjacent normal tissues. "P<0.05 and ${ }^{* * *} \mathrm{P}<0.001$ vs. inhibitor $\mathrm{NC}$, corresponding $\mathrm{NC}$ group or normal adjacent tissue. DIMT1, dimethyladenosine transferase 1 ; miR, microRNA; NC, negative control; WT, wild-type; MUT, mutant; UTR, untranslated region; RT-qPCR, reverse transcription-quantitative PCR. 
A
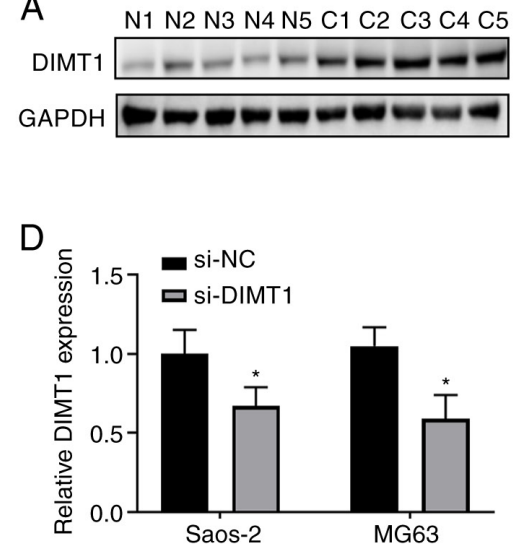

B

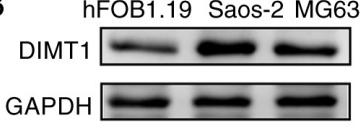

E

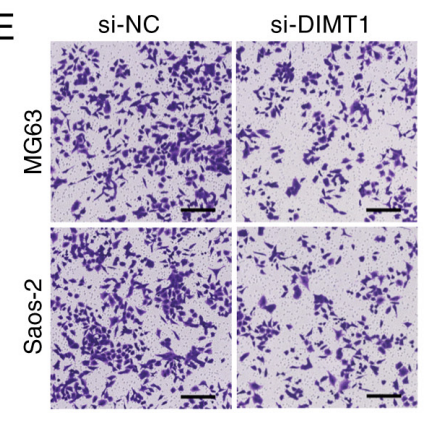

C

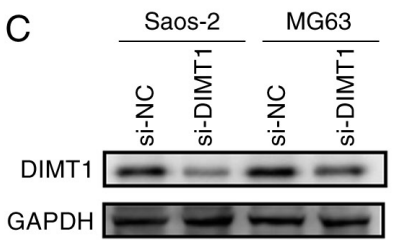

$\mathrm{F}$

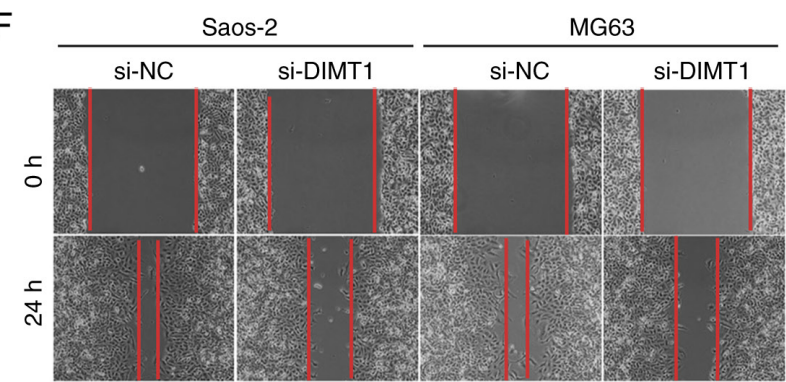

Figure 6. DIMT1 promotes migration and invasion of osteosarcoma. (A) Western blot analysis was performed to detect DIMT1 protein expression in osteosarcoma tissues and adjacent normal tissues ( $\mathrm{n}=5$ ). Tissues were collected from five different patients. GAPDH was used as the loading control. (B) Western blot analysis was performed to detect DIMT1 protein expression in the human osteoblast cell line, hFOB1.19, and osteosarcoma cell lines, Saos-2 and MG63. GAPDH was used as the loading control. (C) Saos-2 and MG63 cells were transfected with $50 \mathrm{nM}$ si-NC or si-DIMT1 for $48 \mathrm{~h}$ and western blot analysis was performed to detect DIMT1 protein expression. GAPDH was used as the loading control. (D) Reverse transcription-quantitative PCR analysis was performed to detect DIMT1 expression in Saos-2 and MG63 cells transfected with si-NC or si-DIMT1 for $48 \mathrm{~h}$. (E) The Transwell assay was performed to detect the invasive ability of Saos-2 and MG63 cells transfected with $50 \mathrm{nM}$ si-NC or si-DIMT1 for $24 \mathrm{~h}$. Quantification analysis is depicted in the middle right panel. Scale bar, $50 \mu \mathrm{m}$ and magnification, x100. (F) Wound healing analysis of Saos-2 and MG63 cells transfected with si-NC or si-DIMT1. Scale bar, $50 \mu \mathrm{m}$. "P<0.05 vs. si-NC or control. DIMT1, dimethyladenosine transferase 1; si, small interfering; NC, negative control; C, osteosarcoma tissues; N, adjacent normal tissues.

overexpression of miR-545-5p decreased the migratory and invasive abilities of osteosarcoma cells.

miR-545-5p target several downstream targets in multiple signaling pathways that might serve critical roles in tumorigenesis and development, such as murine double minute 2, polo-like kinase 1 and $\delta$-anubikevulinic acid dehydratase, suggesting that miR-545-5p functions as a major switch for a series of cellular processes $(21,32,33)$. In the present study, activating miR-545-5p alone inhibited cancer growth by regulating the expression of DIMT1. The in vivo xenograft experiments clearly demonstrated that overexpression of miR-545-5p significantly suppressed xenograft growth. However, not all the observed phenotypes can be explained by alterations in DIMT1 levels due to modified miR-545-5p expression in osteosarcoma. Prospective studies should include administering miR-545-5p to mice with osteosarcoma to determine whether it induces tumor inhibition and prevents a localized osteosarcoma from metastasizing.

A previous study suggested that miR-545-5p expression was upregulated in colorectal cancer SW620 cells (a cell line derived from a metastatic site) compared with SW480 cells (a cell line derived from a local site in the same patient from which the SW620 line was derived) (14). However, the present study did not provide functional data to support the hypothesis that miR-545-5p participates in the transformation of a localized colon cancer cell to a metastatic colon cancer cell. The conclusion that miR-545-5p inhibits metastasis is supported by both the migration and invasion assays, as overexpression of miR-545-5p inhibited cancer cell migration. Notably, the results of the present study demonstrated that DIMT1, a downstream target of miR-545-5p, facilitated the migration and invasion of osteosarcoma cells. Thus, miR-545-5p is an inhibitor of osteosarcoma metastasis. However, the role of miR-545-5p in cancers, particularly in colon cancer, requires further investigation.

The results of the present study revealed that miR-545-5p regulates DIMT1 expression by binding to the 3'-UTR of DIMT1 mRNA. DIMT1, also known as DIM1, was initially identified as a homolog of $18 \mathrm{~S}$ rRNA dimethylase in Saccharomyces cerevisiae (gene ID, 27292). DIMT1 functions as a downstream target of miR-210, which regulates gastric epithelial cell proliferation (34). In addition, DIMT1 has been demonstrated to be elevated in gastric cancer cells, and it is considered a predictor of tumor progression and prognosis in 
A

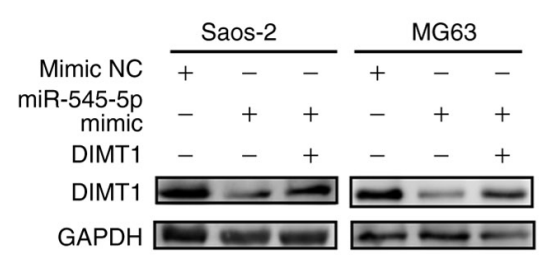

B

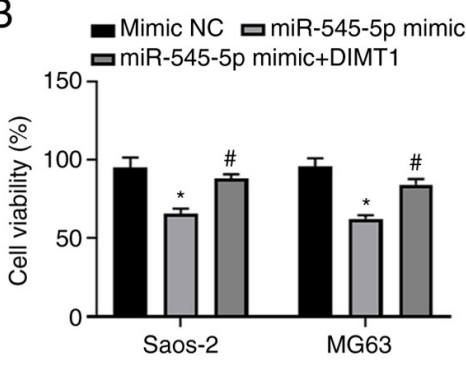

C
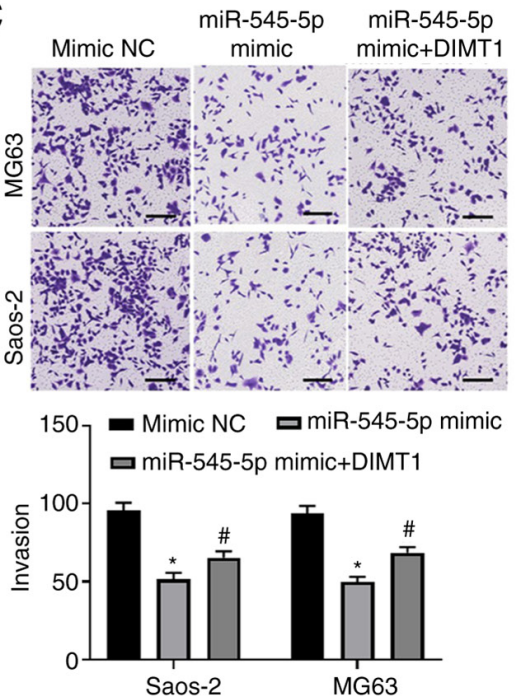

$\overline{\mathrm{a}}$
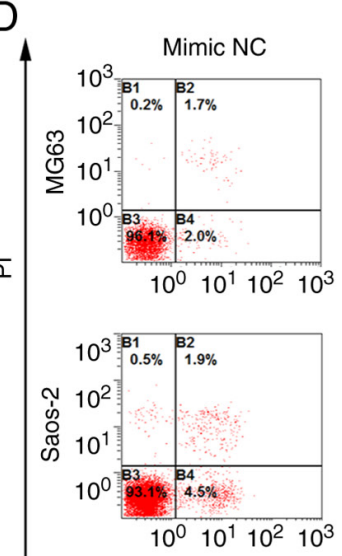
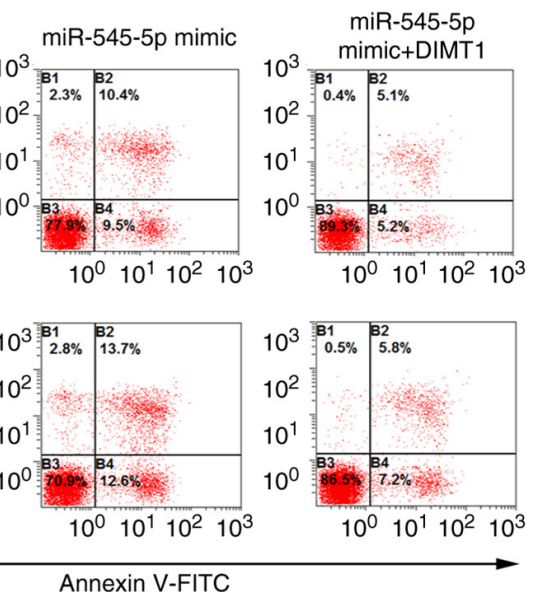

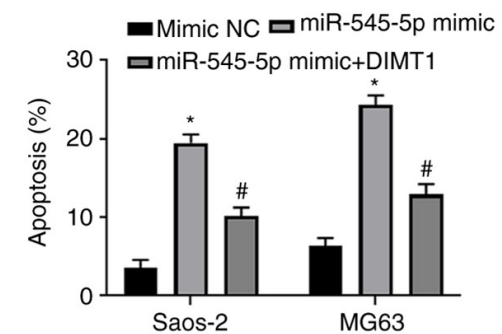

E
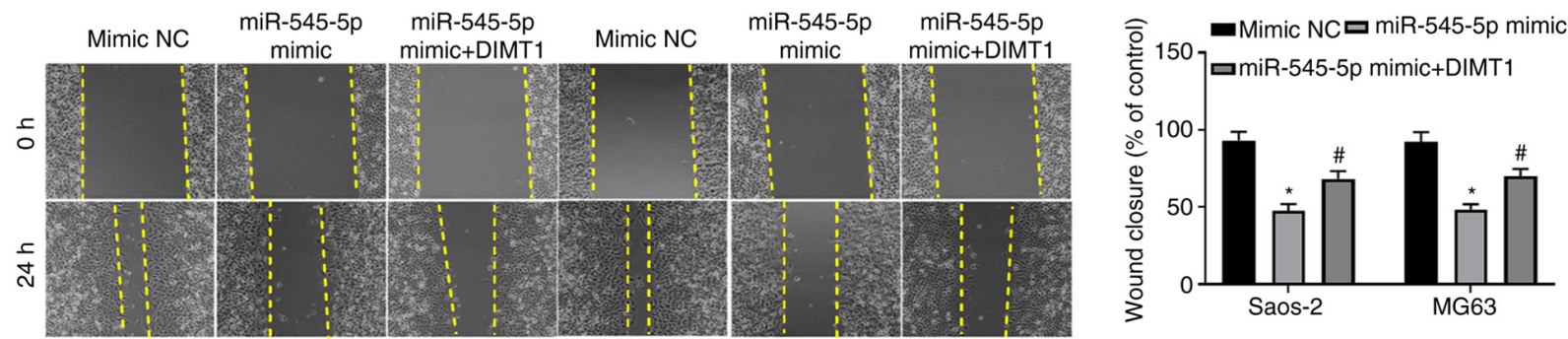

Figure 7. miR-545-5p functions by targeting DIMT1. (A) Saos-2 and MG63 cells were transfected with $50 \mathrm{nM}$ miR-545-5p mimic or mimic NC, with or without co-transfection of $10 \mu \mathrm{g}$ DIMT1 overexpression plasmid for $48 \mathrm{~h}$ and western blot analysis was performed to detect DIMT1 protein expression. GAPDH was used as the loading control. (B) Saos-2 and MG63 cells were transfected with $50 \mathrm{nM}$ miR-545-5p mimic or mimic NC, with or without co-transfection of $10 \mu \mathrm{g}$ DIMT1 overexpression plasmid for $48 \mathrm{~h}$ and the Cell Counting Kit-8 assay was performed to detect cell viability. (C) Saos-2 and MG63 cells were transfected with $50 \mathrm{nM}$ miR-545-5p mimic or mimic NC, with or without co-transfection of $10 \mu \mathrm{g}$ DIMT1 overexpression plasmid for $24 \mathrm{~h}$ and the Transwell assay was performed to detect cell invasion. Quantification analysis is depicted in the lower panel. Scale bar, $50 \mu \mathrm{m}$ and magnification, $\mathrm{x} 100$. (D) Flow cytometric analysis of Saos-2 and MG63 cells transfected with $50 \mathrm{nM}$ miR-545-5p mimic or mimic NC, with or without co-transfection of $10 \mu \mathrm{g}$ DIMT1 overexpression plasmid for $48 \mathrm{~h}$. Cells were harvested and labeled with Annexin V-FITC and PI. The numbers in each quadrant indicate positive percentages of the entire population. (E) Saos-2 and MG63 cells were transfected with $50 \mu \mathrm{m}$ miR-545-5p mimic or mimic NC, with or without co-transfection of $10 \mu \mathrm{g}$ DIMT1 overexpression plasmid and the wound healing assay was performed to detect cell migration. Quantification analysis is depicted in the right panel. Scale bar, $50 \mu \mathrm{m}$. ${ }^{\text {"P }}<0.05$ vs. mimic NC. ${ }^{~} \mathrm{P}<0.05$ vs. miR-545-5p mimic. miR, microRNA; DIMT1, dimethyladenosine transferase 1; NC, negative control; PI, propidium iodide.

patients with gastric carcinoma (35). Furthermore, miR-210 regulates the DIMT1-interferon regulatory factor 4 oncogenic axis in multiple myeloma under hypoxic stress (36). Although an oncogenic role for DIMT1 has been suggested, whether DIMT1 functions as an oncogene in osteosarcoma remains unclear.

DIMT1 is regulated by multiple miRNAs (miR-210 and miR-101) (36,37), and three different miRNAs target DIMT1 simultaneously. Although the expression levels of miR-210 and miR-101 in osteosarcoma cells remain unclear, it is possible that the alteration of different miRNA expression levels creates different phenotypes, rather than alterations in the expression levels of DIMT1. However, to understand the regulatory network controlling DIMT1, further expression analyses are required. The results of the present study suggest that miR-545-5p controls apoptosis, migration and invasion of osteosarcoma cells via DIMT1. However, alterations in all pathways involved were not investigated in the present study. It is important to perform high throughput RNA sequencing for cells with or without high miR-545-5p levels to determine the underlying molecular mechanisms of how miR-545-5p regulates osteosarcoma development.

In conclusion, the results of the present study suggest two potential targets for inhibiting osteosarcoma metastasis, miR-545-5p and DIMT1. One can utilize miR-545-5p mimics in situ or through the circulation to induce an anticancer effect, 
while the other can antagonize DIMT1 via small molecule cancer drugs, although the development of such drugs requires further investigation. Taken together, these results provide novel therapeutic targets for osteosarcoma and molecular insights into their regulatory network.

\section{Acknowledgements}

Not applicable.

\section{Funding}

This study was supported by the Science and Technology Planning Project of Xi'an [grant no. 2019115013YX005SF038(13)].

\section{Availability of data and material}

The datasets used and/or analyzed during the present study are available from the corresponding author upon reasonable request.

\section{Authors' contributions}

HZZ, BC and ZCT conceived the present study and designed the experiments. JJD, NZ and YXS performed the experiments. KZ and XJL contributed to data analysis. HZZ, BC and ZCT drafted the initial manuscript. All authors have read and approved the final manuscript. ZCT and KZ confirm the authenticity of all the raw data.

\section{Ethics approval and consent to participate}

The present study was approved by the Ethics Committee of Honghui Hospital of Xi'an Jiaotong University (Xi'an, China) and written informed consent was provided by all patients prior to the study start. All animal experiments were approved by the Institutional Animal Care and Use Committee of Honghui Hospital of Xi'an Jiaotong University (Xi'an, China). Study approval no. 202003059.

\section{Patient consent for publication}

Not applicable.

\section{Competing interests}

The authors declare that they have no competing interests.

\section{References}

1. Gianferante DM, Mirabello L and Savage SA: Germline and somatic genetics of osteosarcoma-connecting aetiology, biology and therapy. Nat Rev Endocrinol 13: 480-491, 2017.

2. Colding-Rasmussen T, Thorn AP, Horstmann P, Rechnitzer C, Hjalgrim LL, Krarup-Hansen A and Petersen MM: Survival and prognostic factors at time of diagnosis in high-grade appendicular osteosarcoma. Acta Oncol 57: 420-425, 2018.

3. Lindsey BA, Markel JE and Kleinerman ES: Osteosarcoma overview. Rheumatol Ther 4: 25-43, 2017.

4. Kansara M, Teng MW, Smyth MJ and Thomas DM: Translational biology of osteosarcoma. Nat Rev Cancer 14: 722-735, 2014.

5. Vos HI, Coenen MJ, Guchelaar HJ and Te Loo DM: The role of pharmacogenetics in the treatment of osteosarcoma. Drug Discov Today 21: 1775-1786, 2016.
6. Xie L, Yao Z, Zhang Y,Li D, Hu F, Liao Y,Zhou L, Zhou Y, Huang Z, He Z, et al: Deep RNA sequencing reveals the dynamic regulation of miRNA, lncRNAs, and mRNAs in osteosarcoma tumorigenesis and pulmonary metastasis. Cell Death Dis 9: 772, 2018.

7. Ma J, Huang K, Ma Y, Zhou M and Fan S: The TAZmiR-224-SMAD4 axis promotes tumorigenesis in osteosarcoma. Cell Death Dis 8: e2539, 2017.

8. Ji Q, Xu X, Li L, Goodman SB, Bi W, Xu M, Xu Y, Fan Z, Maloney WJ, Ye Q and Wang Y: miR-216a inhibits osteosarcoma cell proliferation, invasion and metastasis by targeting CDK14. Cell Death Dis 8: e3103, 2017.

9. Raza U, Zhang JD and Sahin O: MicroRNAs: Master regulators of drug resistance, stemness, and metastasis. J Mol Med (Berl) 92: 321-336, 2014.

10. Sampson VB, Yoo S, Kumar A, Vetter NS and Kolb EA: MicroRNAs and potential targets in osteosarcoma: Review. Front Pediatr 3: 69, 2015.

11. Wang C, Jing $\mathrm{J}$ and Cheng L: Emerging roles of non-coding RNAs in the pathogenesis, diagnosis and prognosis of osteosarcoma. Invest New Drugs 36: 1116-1132, 2018.

12. $\mathrm{Su} \mathrm{P}, \mathrm{Mu} \mathrm{S}$ and Wang Z: Long noncoding RNA SNHG16 promotes osteosarcoma cells migration and invasion via sponging miR-340. DNA Cell Biol 38: 170-175, 2019.

13. Pu Y, Zhao F, Cai W, Meng X, Li Y and Cai S: miR-193a-3p and miR-193a-5p suppress the metastasis of human osteosarcoma cells by downregulating Rab27B and SRR, respectively. Clin Exp Metastasis 33: 359-372, 2016.

14. Yan W, Yang W, Liu Z and Wu G: Characterization of microRNA expression in primary human colon adenocarcinoma cells (SW480) and their lymph node metastatic derivatives (SW620). OncoTargets Ther 11: 4701-4709, 2018.

15. Li C, Wang M, Wang Y, Zhang J and Sun N: A new model of the mechanism underlying lead poisoning: SNPs in miRNA target region influence the delta-aminolevulinic acid dehydratase expression level. Epigenomics 9: 1353-1361, 2017.

16. Bergdahl IA, Grubb A, Schutz A, Desnick RJ, Wetmur JG, Sassa S and Skerfving S: Lead binding to delta-aminolevulinic acid dehydratase (ALAD) in human erythrocytes. Pharmacol Toxicol 81: 153-158, 1997.

17. Wang C, Han XS, Li FF, Huang S, Qin YW, Zhao XX and Jing Q: Forkhead containing transcription factor Albino controls tetrapyrrole-based body pigmentation in planarian. Cell Discov 2: $16029,2016$.

18. Liu Z, Dou C, Yao B, Xu M, Ding L, Wang Y, Jia Y, Li Q, Zhang $\mathrm{H}$, Tu K, et al: Ftx non coding RNA-derived miR-545 promotes cell proliferation by targeting RIG-I in hepatocellular carcinoma. Oncotarget 7: 25350-25365, 2016.

19. Hu C, Wang Y, Li A, Zhang J, Xue F and Zhu L: Overexpressed circ_0067934 acts as an oncogene to facilitate cervical cancer progression via the miR-545/EIF3C axis. J Cell Physiol 234: 9225-9232, 2019.

20. Yuan G, Wu H, Du Y and He F: Tumor suppressor role of microRNA-545 in oral squamous cell carcinoma. Oncol Lett 17: 2063-2068, 2019.

21. Miao Z, Liu S, Xiao X and Li D: LINC00342 regulates cell proliferation, apoptosis, migration and invasion in colon adenocarcinoma via miR-545-5p/MDM2 axis. Gene 743: 144604, 2020.

22. Livak KJ, and Schmittgen TD: Analysis of relative gene expression data using real-time quantitative PCR and the 2(-Delta Delta C(T)) method. Methods 25: 402-408, 2001

23. Lu YF, Yu JR, Yang Z, Zhu GX, Gao P, Wang H, Chen SY, Zhang J, Liu MY, Niu Y, et al: Promoter hypomethylation mediated upregulation of MicroRNA-10b-3p targets FOXO3 to promote the progression of esophageal squamous cell carcinoma (ESCC). J Exp Clin Cancer Res 37: 301, 2018.

24. Nunes JPS and Dias AAM: ImageJ macros for the user-friendly analysis of soft-agar and wound-healing assays. Biotechniques 62 : 175-179, 2017.

25. Marshall J: Transwell $\left({ }^{\circledR}\right)$ invasion assays. Methods Mol Biol 769: 97-110, 2011.

26. Chen X, Cao X, Sun X, Lei R, Chen P, Zhao Y, Jiang Y, Yin J, Chen $\mathrm{R}$, Ye $\mathrm{D}$, et al: Bcl-3 regulates TGFbeta signaling by stabilizing Smad3 during breast cancer pulmonary metastasis. Cell Death Dis 7: e2508, 2016.

27. National Research Council: National Institutes of Health Guide for the Care and Use of Laboratory Animals: 8th Edition. The National Academies Press, Washington, DC, 2011.

28. Laferriere CA and Pang DS: Review of intraperitoneal injection of sodium pentobarbital as a method of euthanasia in laboratory rodents. J Am Assoc Lab Anim Sci 59: 254-263, 2020. 
29. Shannon P, Markiel A, Ozier O, Baliga NS, Wang JT, Ramage D, Amin N, Schwikowski B and Ideker T: Cytoscape: A software environment for integrated models of biomolecular interaction networks. Genome Res 13: 2498-2504, 2003.

30. Yu AM, Jian C, Yu AH and Tu MJ: RNA therapy: Are we using the right molecules? Pharmacol Ther 196: 91-104, 2019

31. Nugent M: microRNA and bone cancer. Adv Exp Med Biol 889: 201-230, 2015

32. Xie M, Ma L, Xu T, Pan Y, Wang Q, Wei Y and Shu Y: Potential regulatory roles of MicroRNAs and long noncoding RNAs in anticancer therapies. Mol Ther Nucleic Acids 13: 233-243, 2018.

33. Zhang H, Zhang K, Xu Z, Xu Z, Chen Z, Wang Q, Wang C and Cui J: MicroRNA-545 suppresses progression of ovarian cancer through mediating PLK1 expression by a direct binding and an direct regulation involving KDM4B-mediated demethylation. BMC Cancer 21: 163, 2021.

34. Ikeda S, Kitadate A, Abe F, Saitoh H, Michishita Y, Hatano Y, Kawabata Y, Kitabayashi A, Teshima K, Kume M, et al: Hypoxia-inducible microRNA-210 regulates the DIMT1-IRF4 oncogenic axis in multiple myeloma. Cancer Sci 108: 641-652, 2017.
35. Liu G, Peng X, Cai Y, Cheng A, Zha L and Wang Z: DIMT1 overexpression correlates with progression and prognosis in gastric carcinoma. Hum Pathol 70: 35-42, 2017.

36. Kiga K, Mimuro H, Suzuki M, Shinozaki-Ushiku A, Kobayashi T, Sanada T, Kim M, Ogawa M, Iwasaki YW, Kayo $\mathrm{H}$, et al: Epigenetic silencing of miR-210 increases the proliferation of gastric epithelium during chronic Helicobacter pylori infection. Nat Commun 5: 4497, 2014

37. Guo ZX, Zhou FZ, Song W, Yu LL, Yan WJ, Yin LH, Sang H and Zhang HY: Suppression of microRNA-101 attenuates hypoxia-induced myocardial H9c2 cell injury by targeting DIMT1-Sp1/survivin pathway. Eur Rev Med Pharmacol Sci 22: 6965-6976, 2018.

(c) (7) (9) This work is licensed under a Creative Commons

c) $\mathrm{EY}$ NO NO Attribution-NonCommercial-NoDerivatives 4.0 International (CC BY-NC-ND 4.0) License. 